\title{
CEREBRAL TRAUMA IN INFANCY AND INTELLECTUAL DEFECT
}

\author{
BY
}

\section{R. C. OLDFIELD and MOYRA WILLIAMS*}

\author{
From the Institute of Experimental Psychology, Oxford
}

Discussion of the functions of the prefrontal areas of the cerebral cortex has evoked a bewildering variety of observations and hypotheses. Among the more incisive of recent features has been the observation, repeated by other workers, of Hebb and Penfield (1940) that it is possible for an adult human being to be deprived of both of these areas and exhibit little or no intellectual loss, at least to the extent that such loss can at present be assessed by formal or clinical psychological tests. Indeed, in cases in which the prefrontal area is removed on one side at operation after a period in which cerebral function was disordered by some pathological condition, such as epilepsy, intellectual function may markedly improve (Krynauw, 1950; Cairns, 1951). Controversies have arisen between those, such as Hebb, who have been struck by the apparently negligible disturbance which may be occasioned by complete loss of these areas, and those, like Goldstein (1936, 1944) who, largely basing their conclusions on the study of cases in which the parts are present but damaged, diseased, or degenerated, emphasize that specific failings of intellectual processes can be demonstrated by an appropriate test. It seems likely that some at least of these differences of opinion might be resolved if more were known of the difference between absence and disordered function of brain tissue and the effect on intellectual processes. The central nervous system affords little warrant for the idea that disease is equivalent simply to partial extirpation so far as disturbance of function is concerned. Goldstein contends that an important function of the prefrontal areas is the maintenance of varied systems of categories of thought and of abstract as opposed to concrete attitudes in high-grade behaviour. He supports this view, in fact, by reference to cases where tissue is present but damaged. Hebb, in criticizing him, tends to rely on showing that Goldstein's tests do not reveal these functional defects in cases where the tissue in question has been removed at operation.

A second interesting and related topic for specu-

\footnotetext{
* Working with a grant from the Nuffield Foundation.
}

lation centres around the question whether cerebral, and in particular frontal, trauma sustained at an early age has the same later effects as those produced by damage in adult life. Ritchie Russell $\stackrel{\circ}{\circ}$ (1948) suggests, for instance, “. . . that by early i or middle adult life the frontal lobes have already $\vec{\circ}$ done much of their work by conditioning and moulding the pattern of the behaviour responses of $\vec{\omega}$ the left parieto-temporal area. If this view is correct, injury to the prefrontal lobes in young children should lead to a very obvious failure of mental development, but it is difficult to get reliable information about cases of this kind". Of the two cases adduced by Russell, one is that reported bo Norman (1945) in which very severe generalized 을 mental defect followed an acute encephalopath episode in a child, previously normal and health $\frac{1}{8}$ at the age of 13 months. The patient died of pulmonary tuberculosis at the age of 19 years and necropsy revealed complete atrophy of both frontal lobes backwards to involve the lower part of the precentral gyri, leaving the upper part unaffected, and no cortical damage elsewhere. The other case cited by Russell is that further reported in the present paper.

Hebb (1942) is disinclined (vide supra) to accept the specific intellectual signs defined by Goldstein as inevitably consequent on severe frontal lobe $\mathbb{Q}$ damage. But he also seeks to distinguish between the outcome at the psychological level of a lesion sustained early and that of one suffered in adult life. This he proposes to do on the established basis that when a lesion occurs in adult life, abilities involving language, and in particular the capacity to define the meaning of words (vocabulary test), tend to be preserved provided no aphasia is present. The scoring on performance tests, on the other hand, is liable to be relatively depressed, to a greater or less extent. He is thus led to enquire whether the same differential tendency manifests itself in cases where $\stackrel{\bigcirc}{\supset}$ the cerebral damage occurs in infancy. He has $\rightarrow$ perforce to make use of "birth injury" case material to which certain obvious disadvantages attach, but $N$ is able to show that the characteristic pattern is one in which scores for verbal tests are not only not higher 32 
in relation to those for performance tests, but tend actually to be lower. He concludes that "the weight of evidence points to a more widespread and less selective effect of the large infant injury than of the adult injury". (It should be remarked that in this investigation $\mathrm{Hebb}$ is not primarily concerned with lesions confined to the frontal areas.) He goes on to remark that " . . . more cerebral efficiency or more intellectual power is needed for intellectual development than for later functioning at the same level" (his italics), a conclusion, if more general, not far removed from that of Ritchie Russell.

The difficulties involved in any conclusive test of such a hypothesis are numerous and manifest. Case material ("birth injuries" apart) which may throw light on the question is very scarce, and in no single instance likely to conform in all respects to what might be desired. In Norman's case, for instance, the lesion was bilateral, frontal, and virtually complete. Its extent and character and the structural normality of the rest of the cerebral cortex were established at necropsy. But the resultant dementia was so profound as to preclude any detailed qualitative study. The case described in the present paper, on the other hand, seems worthy of reporting because it lends itself to closer psychological assessment of the intellectual defect. But the absence of an air study (permission for which was refused) and of post-mortem findings make it impossible to be precise as to the extent of the lesion.

\section{Case History}

$\mathrm{X}$, then aged $5 \frac{1}{2}$ months, was admitted to hospital in Liverpool on November 29, 1940, having sustained a penetrating head wound in an air raid. He had a lacerated scalp wound in the right parieto-frontal region with a piece of glass in the skull and was slightly shocked but apparently otherwise uninjured. At operation the following day the wound edges were excised, the glass removed from the skull and the wound sutured. No further exploration seems to have been made. Later that day the baby was described as being very pale but feeding well and not vomiting. At 10 p.m. the same evening both hands were twitching. Two days later tone and power of the limbs seemed normal, the pupils equal and reacting to light, knee jerks present and equal, and the general condition fairly good, but he was still very pale. His subsequent recovery seems to have been almost uneventful and at no time then, or subsequently up to the present day, were any neurological signs seen. On February 13, 1941, a purulent discharge from the right ear was noted, but this cleared up, and on March 4, 1941, he was said to be quite well. Radiographs (Figs. 1 and 2) revealed a foreign body (? glass) lying deep in the right frontal lobe. This is described later.

At a follow-up examination on July 31, 1941, when the child was 13 months old, no abnormality was detected, and his general development seemed to be that of a normal, healthy child. He was beginning to talk a little and trying to walk. He was said to be good tempered. At 21 months, on March 16, 1942, he was walking and talking and the matron in charge of the home in which he had been placed said he appeared perfectly normal to her. Towards the end of October in the same year, when he had been transferred to another home, he did not speak for a month, but was otherwise normal, though perhaps lacking in initiative. He understood and obeyed simple commands.

Up to the age of about 2 years, then, there was no direct evidence that the very severe injury to the right frontal lobe (with possible secondary involvement of the left) had exercised any effect upon this child's develop-
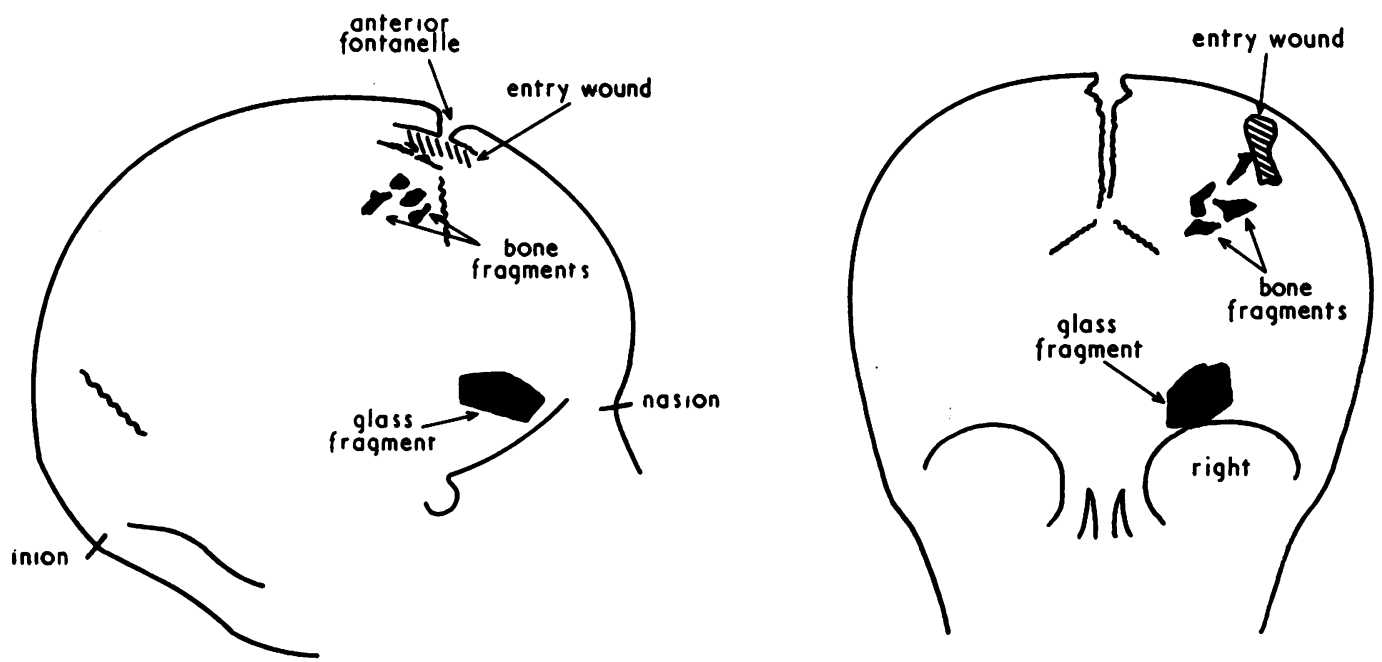

FiGs. 1 and 2.-Tracings of skull radiographs taken three days after the injury in 1940 when the patient was $5 \frac{1}{2}$ months old. 
ment. His home circumstances would, however, have been a potential handicap to any child.

He was sixth in a family of eight, of which an elder brother was killed in the same air raid in which he was injured. The others are said to have made normal progress at school. The two younger children ( $2 \frac{1}{2}$ years old) talked to their parents but not to strangers. The family was of low economic status, living in "two rooms and a box" so dark that the gas had to be kept alight all day. The father, a pastrycook and confectioner, gave the impression from interviews and letters of being hysterical, aggressive, and of a litigious tendency. $\mathrm{He}$ was inclined to devote much of his attention to gaining as much as possible from the social welfare and other authorities out of his son's injury. Called up in 1942, he was medically discharged in 1943 suffering from "arthritis", a disease he seems to have contracted during his brief service with the forces. In March, 1943, the mother was provided with a certificate to the effect that she was suffering from neurasthenia and was unfit to be in sole charge of the boy. In consequence of this situation the child was placed in a series of homes. The father's account of his behaviour between 1943 and 1947 was one of steady deterioration. He was said to have been sent home from school by the medical officer because he hit small girls and tried to strangle the school cat. At home he made an unprovoked assault on his mother and younger sisters, causing the former to fall downstairs. He was frequently found eating food from dustbins, dog's food, and faeces. There is no direct check on these allegations, but in 1947 he was under psychiatric and neurological observation as a result of his father's persistent wish to get him committed to institutional care. In January, 1947, he was admitted to hospital in Liverpool for observation and treatment of sores on his toes, apparently caused by biting himself.

Admitted to Stoke Mandeville hospital in February,

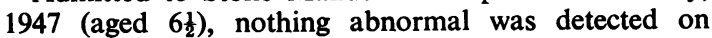
physical examination, but he was said to be uncooperative and easily distracted and it was on this account difficult to assess his intelligence. His behaviour in the ward was intractable and disturbed to a degree suggestive of psychosis. He used abusive and obscene language. $\mathrm{He}$ was increasingly irritable and aggressive and deliberately wet his bed and poured tea on it. On February 20, 1947, however, Dr. Ritchie Russell thought that he was responding to firm treatment and with skilled care should improve greatly. There was considered to be no indication for operation and Dr. Russell judged that in spite of his mental backwardness and antisocial behaviour it should be possible to bring him up to be a useful member of society. On psychiatric examination in March, 1947, Dr. Wyatt found a mental age (revised Stanford Binet scale) of 4 years 10 months (I.Q. 74) and on performance tests a mental age of 5 years. The scores showed a marked degree of scatter, indicating emotional instability, and his behaviour on testing confirmed this. Dr. Wyatt noted a disturbance of emotional control, in some respects almost psychotic, and felt this might be related to a possible extension of the trauma, as shown on the radiographs, to the hypothalamus. From time to time, he found, the patient exhibited "brief flashes of fairly normal intelligence" which lapsed almost at once, and his view was that the $Z$ boy was certifiable under the Mental Deficiency Acts and the outlook unfavourable for any appreciable improvement.

He was placed in various special educational establish- $\bullet$ ments and his father made representations, and as a result, at the age of 15 , he was awarded a $100 \%$ disability pension on account of his injury and its consequences. This fact does not seem to have been disclosed to the boy then or later: nor, indeed, does he appear to have been told anything of the injury. He left school at $16 \vec{F}$ and was employed in a laundry for eight months. After $\stackrel{0}{-}$ three months in a butcher's firm he worked for 13 months washing bottles in a dairy, and for a time earned $f 11$ a $\frac{\bar{O}}{\bar{D}}$ week on a milk wagon. According to his subsequent $\frac{\sigma}{\partial}$ account, he left the laundry and the butcher because of $\mathbb{D}$ weakness and pain in his left arm, a disability he managed to disguise in the dairy by simply not using it. os The welfare officer, however, could not recollect his $\vec{\circ}$ mentioning this trouble at the time. During this period he was living at home, from which he ran away on four $\vec{\omega}$ occasions, and he endeavoured to volunteer for the Army.

When medically boarded for National Service on October 22, 1958, he was given a Pulheems assessment of

$$
\begin{array}{lllllllll}
\mathbf{P} & \mathbf{U} & \mathbf{L} & \mathrm{H} & \mathrm{E} & \mathbf{E} & \mathbf{M} & \mathbf{S} & \text { C.P. } \\
2 & 2 & 2 & 2 & 2 & 1 & 2 & 2 & +2
\end{array}
$$

He did not disclose, probably because he did not the know, that he had sustained the injury in infancy, n⿳亠丷厂 음 that he was in receipt of a war pension. (His fathe received the payments of the latter as he was a minor Posted to a Royal Artillery unit at the beginning ब्ञ January, 1959, the personnel selection officer noted his low mental grade and referred him to the area psychif trist, who recommended him to be down-graded M2.S3 "on grounds of great personal inadequacy", afa $\vec{\varphi}$ noted "a solid summed illiterate S.G. 5". In con" sequence he was re-posted to the Armed Royal Pioneer Corps. Here he complained of pain in the left arm resulting from small arms drill. In the meantime his father had initiated enquiries with the Ministry regarding $\bar{\partial}$ his service. He was admitted to a military hospital on September 11, 1959, for observation.

On physical examination nothing abnormal was detected. It was noted that although the patient com-음 plained of weakness in the right upper limb the power 3 was good and the tone symmetrical. The fields were full, and acuity (uncorrected) $6 / 6$ in both eyes. The Wassermann reaction was negative in both blood and cerebrospinal fluid; there were no blood cells in the latter, and protein was $25 \mathrm{mg}$. per $100 \mathrm{ml}$. Radiographs showed multiple opacities in the right fronto-parietal 3 region. Some of these appeared to be bone fragments lying off the direct track of a foreign body which lay above the right orbit. The character and position of this are better assessed from the films taken immediately after the injury, in which the outline is sharper. The $D$ appearances are quite consistent with this foreign body을. being a piece of window glass, similar to that originally extracted at operation from the wound of entry. Dr. $\Omega$ Russell was of the opinion that the injury resembled a N right-sided leucotomy. 
The E.E.G. report on May 21, 1959, was: A $10 \mathrm{c} / \mathrm{s}$ rhythm was dominant bilaterally and inhibited on eyeopening. Overbreathing produced no change. Within normal limits.

Mentally, he was found to be "of pleasant disposition, but very low intelligence". He was fully orientated in time and space. His reading was very poor. His recent memory was assessed as "fair", remote as "poor". On brief informal psychometric testing his performance was very poor, but without specific outstanding features. It was noted on June 16, 1959, regarding his general comportment during five weeks of ward life, that he showed no gross behaviour disturbance. On one occasion he was seen to partake of a neighbour's meal while sitting at supper. He tended to forget instructions, and, occasionally, to disobey them. He was dirty and unkempt. Just before discharge he burned his left hand by spilling petrol on it while filling a lighter and inadvertently setting light to it. The precise status of this "accident" was not determined.

More detailed psychological examination (R.C.O.) was undertaken with a view to detecting any signs of "frontal lobe" type of intellectual defect that might be present. He appeared dull and uneducated, but not disorientated within his own rather constricted environment. He could not, or refused to try to, draw a map of England to show where Oxford and Liverpool lie, but was able to draw an accurate plan of his ward to show the position of his bed. In the same way he was orientated with regard to the immediate past but hazy about remoter events. He was able to give a coherent account of the more superficial aspects of his life in the Army and previously of civil life, and of his attitudes to them. But closer questioning induced incoherence and he drifted off into other topics with which he was preoccupied.

Block designs (four blocks) were carried out quite expeditiously, he made appropriate changes to correct initial mistakes fairly adequately, and showed no perseverative tendencies. In the Vigotsky sorting test he was able spontaneously to sort by colour, and when asked to find a second method had no difficulty in sorting by shape. Asked to find a third way, he made an attempt, though inadequately, to sort by size. He sorted coloured wools (Goldstein-Scheerer test) as rapidly and effectively as a normal individual, showing no tendency to be either overcareless or overpernickety about the categories he adopted, nor did he lose track of the system he was using. His immediate verbal memory (sentence repetition test) showed fairly gross defect, with little capacity to improve over three successive trials of the same sentence. He was capable of immediate reproduction of simple line figures by drawing, without gross inaccuracy or loss of spatial framework.

The general impression was one of low-grade general intelligence without specific elements of defect of orientation, failure of "abstract attitude" or of "categoreal behaviour" (Goldstein), such as may commonly be found in adult patients with severe frontal damage or deterioration.

A fuller, formal, psychometric assessment was carried out on June 26, 1959 (M.W.). Performance on the
Wechsler (WAIS) shows a verbal I.Q. of 79 and performance I.Q. of 59. Sub-test (standard) scores were as follows:-

\begin{tabular}{|c|c|c|c|}
\hline $\mathbf{H}$ & Information .. & - & \\
\hline $\mathbf{H}$ & Comprehension & .. & .. \\
\hline $\mathbf{N}$ & Arithmetic .. & .. & .. \\
\hline $\mathbf{N}$ & Similarities .. & .. & .. \\
\hline $\mathbf{N}$ & Digit span .. & & \\
\hline $\mathbf{H}$ & Vocabulary & .. & .. \\
\hline$N$ & Digit symbol & .. & .. \\
\hline & Picture comparison & & .. \\
\hline & Object assessment & & \\
\hline
\end{tabular}

It should be explained that these scores are in each case to be related to an average adult score of 10 . The left-hand column indicates in which tests the score holds or does not hold its pre-morbid level in general mental deterioration of organic origin.

There were no signs of any specific defects or any indications of traumatic as opposed to congenital mental defect.

His memory on the digit span test and on a test of delayed recall was quite normal for a person of his I.Q.

Performance on the Rorschach test was rather limited, probably due to his low I.Q. The only abnormal feature apart from this was an inability to form any constructions involving colour, a suggestion that he is unable to integrate emotional stimuli. There were occasional signs of tension, and a tendency to go for minute details in an obsessional manner, but not to an extent greater than that often encountered in youths of his age.

\section{Discussion}

The history of this boy presents a number of puzzling features difficult to reconcile on any single assumption. The trauma he suffered at the age of $5 \frac{1}{2}$ months must have caused very severe and extensive damage to the right frontal lobe. Figures 1 and 2 show tracings from the radiograph taken immediately after the injury of the shadow of the foreign body, and although no precise determination of its shape, size and position can be made from these pictures, Dr. W. M. Cowan, of the Department of Human Anatomy, Oxford, has been kind enough to try to assess which brain structures are likely to have been involved, by sectioning an adult brain in relation to the track of the foreign body and inserting a piece of cardboard to represent the latter. His conclusion is that the glass lies in the white matter above the orbital surface just anterior to the putamen and just lateral to the caudate nucleus. In reaching this position it may have cut through the tip of the anterior horn of the ventricle, but probably did not touch the tip of the temporal lobe. The track appears to lie frontal to the precentral gyrus, and the entire lesion seems clearly confined to the right of the midline.

Up to and including the age of walking and talking, experienced attendants were unable to 
detect any evidence of interference with the patient's normal mental and behavioural development. Outspoken behaviour disorder, however, declared itself when he was about 3 years old. At this time his mother had just gained official sanction for relief from her responsibilities and the father was avowedly anxious to commit the child to institutional care. The material circumstances of his home at this time, too, were unfavourable. The extent of the behaviour disturbance may have been exaggerated by the father at the outset, but that it was gross and persistent was fully confirmed by dociors and nurses in 1947 when he was $6 \frac{1}{2}$ years old. Yet, apart from the cranial scar, there was a complete absence of any neurological or other physical consequence of his injury. Had this injury not been known of, nothing at this time would have contraindicated a diagnosis of behaviour disorder with mental retardation or deficiency. And his personal and family history could scarcely have been thought inappropriate to this condition and indeed might well have been held responsible for it.

At the age of 18 the picture has somewhat changed in emphasis. The outstanding impression is one of low-grade mentality, whether congenital or acquired, with some suggestion of mild behaviour disturbance. He might be considered to have made a good recovery from an earlier behaviour disorder which bordered on the psychotic. Nevertheless nothing in his condition would have suggested revision of a diagnosis which made no appeal to cerebral trauma. Indeed the results of full psychological assessment would bear this conclusion out. No evidence of psychological defect specifically characteristic of frontal lobe damage was found. The deficit was of a generalized kind with no special incapacity to evoke abstract attitudes and to use categories.

Had this boy been mentally defective at birth to an extent that would account for his later condition, one might expect that this would have been manifest in retarded development of walking and talking. In fact, despite the handicap of a severe cerebral injury, he was said to have developed quite normally at this stage. Equally, if he had been normal at birth and it was the cerebral injury which later produced the behaviour disorder and intelligence defect, its effects might have been expected to include earlier retardation of development of speech and loco- motion. The most reasonable conclusion would seem to be that the child's condition after the age of 3 was due to a combination of unfavourable factors, including poor upbringing, a cerebral insult, and possibly some congenital defect.

Whether or not the brain trauma has played any part in inducing his present condition, what stands out as clearly established is the association of an early massive frontal injury with and absence of specific mental defect of the type which might be expected to follow such injury in an adult. In $\vec{F}$ this respect, the case bears out the contention of Hebb and of Russell that when massive injury is sustained at an early age the outcome tends to be lacking in specific features and the dementia to be less distinguishable from the global congenital type. But there is occasion for some surprise, in the light is of Hebb's findings, that even though the lesion may $\overrightarrow{0}$ have left the left frontal speech areas unaffected, no disturbance of language functions resulted. Hebb reports that early lesions not in the speech areas tend to result in a linguistic disability which manifests itself in low scores on verbal tests relative to those on performance tests. The opposite disparity is found in the test results in our case. To whap extent this feature might support the view that the $N$ patient's dementia is not at all the outcome of hi\& injury is not easy to decide.

Perhaps we may be permitted to conclude with plea that all cases of infants sustaining severo cerebral trauma, whether or not there are manifesa effects, should be carefully observed throughout their. course, with full psychological assessment a appropriate intervals, and that the results should be . published. Collation of the resulting data could afford a fresh approach to the intellectual functions of the brain.

We are much indebted to Dr. W. Ritchie Russell for the opportunity of studying this case and for permission to report upon it, and to Dr. Cowan for his anatomical assistance.

\section{REFERENCES}

Cairns, H. (1951). Lancet, 2, 411.

Goldstein, K. (1936). J. Neurol. Psychopath., 17, 27.

(1944). J. Psychol., 17, 187.

Hebb, D. O. (1942). Proc. Amer. Phil. Soc., 85, 275. and Penfield, W. (1940). Arch. Neurol. Psychiat. (Chicago), 44, 421.

Krynauw, R. A. (1950). J. Neurol. Neurosurg. Psychiat., 13, 243. Norman, R. M. (1945). Ibid., 8, 52.

Russell, W. R. (1948). Lancet, 1, 356. 